\title{
IMPACT OF SOCIO-ECONOMIC AND CLIMATE CHANGE ON A TROPICAL CYCLONE LOSSES IN VIETNAM
}

\author{
Lap Quoc TRAN ${ }^{1}$ and Kenji TANIGUCHI ${ }^{2}$ \\ 1 Student member of JSCE, Graduate School of Natural Science and Technology, Kanazawa \\ University \\ (Kakuma-Machi, Kanazawa, Ishikawa 920-1192, Japan) \\ E-mail: lapwru.edu@gmail.com \\ 2 Member of JSCE, Associate Professor, School of Environmental Design, Kanazawa University \\ (Kakuma-Machi, Kanazawa, Ishikawa 920-1192, Japan) \\ E-mail: taniguti@se.kanazawa-u.ac.jp
}

\begin{abstract}
The tropical cyclones that make landfall in the coastal areas of Vietnam cause increasing economic losses, with an average of six landfalls per year leading to approximately VND 12,500 billion in damages. It is assumed that the losses are mainly due to socio-economic developments, i.e. growing wealth and greater settlement of exposed areas. However, it is also thought that the rise in damages is caused by increasing frequency of severe cyclones resulting from climate change. In this paper, we estimate the impact of socioeconomic and global warming on the tropical cyclones losses. We investigate the historical impact functions of storm damage by using the Ordinary Least Squares estimator and regress damages on tropical cyclone characteristics. Based on simulation results of Typhoon Lekima in 2007 under global warming, socioeconomic development scenarios SSPs (Shared Socioeconomic reference Pathways) and the population density of Vietnam, we estimate the impact of climate and socioeconomic changes on tropical cyclone losses in the end of $21^{\text {st }}$ century. Economic losses caused by typhoon will change under global warming at landfall. Socioeconomic changes will increase losses by approximately three and sixteen times greater than that due to climate-induced changes corresponding to SSP3 and SSP5 scenarios.
\end{abstract}

Keywords: tropical cyclones, climate change, socioeconomic impact, storm damage function

\section{INTRODUCTION}

Tropical cyclones (TCs) have been the subject of much concern, among scientists and policy makers since the devastation wrought by Hurricane Katrina in late August 2005. Particular attention has been paid to the possible role of human-caused climate change in patterns of tropical cyclone activity.

Climate change will amplify existing risks and create new risks for natural and human systems ${ }^{1}$. One explanation for this trend is that there are more people and assets in danger ${ }^{2}$. When the influence of rising vulnerability from income and population are accurately controlled, it is hard to know whether the trend in damage is due to a tendency in the potential hazards.

Nordhaus (2006), using a damage function based on aggregate loss data by storm, predicts tropical cyclones losses would, therefore, double by 2100 , an increase of $0.06 \%$ of GDP. Using the FUND model, global hurricane damages were estimated and it increase by $0.007 \%$ a year ${ }^{3)}$.

Located along the east coast of the Indochina Peninsula with a substantial latitudinal extent on the northwest Pacific Ocean, Vietnam is frequently affected by tropical cyclones, which account for about $80 \%$ of the disaster affecting Vietnam. Every year there is an average of four to six typhoons make landfall in the coastal area of Vietnam, leading to approximately VND 12,500 billion in damages ${ }^{4}$. The economic losses caused by tropical cyclones has risen considerably in the last decade (Fig 1), largely due to socioeconomic related and climate change developments. The former being primarily population growth, greater per capita wealth, and increasing settlement of exposed areas are the main reason for increasing tropical cyclone losses in Vietnam.

For example, in 2007, Typhoon Lekima formed in the South China Sea accompanied by strong winds of about $130 \mathrm{~km} /$ hour and heavy rain, mainly affected the provinces of Vietnam on 3 and 4 October 2007, caused massive economic losses. According to the reports of local authorities, the number of dead and missing was 37 and 24 respectively. The typhoon Lekima damages estimated approximately VND 600 billion. 


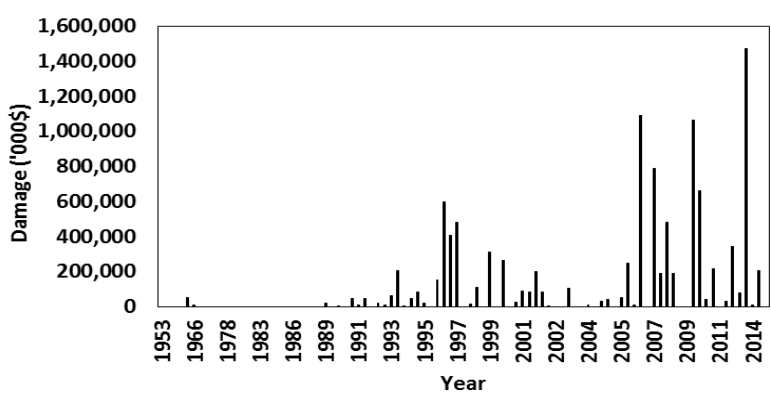

Fig 1. Economic losses caused by tropical cyclone from 1953 to 2014 (Source: EM-DAT).

In this paper, based on the Typhoon Lekima, we investigate the impact of socioeconomic and climate change on losses in coastal areas of Vietnam in both current and the future conditions. First, damage function is estimated using an ordinary least square estimator on historical tropical cyclones and socioeconomic data. Then, the expected loss function is used to calculate the losses from storm both for the current and at the end of $21^{\text {st }}$-century conditions under eight global climate models (GCMs). From these results, the impact of climate and socioeconomic changes on tropical cyclone damages is computed.

The paper is organized as follows: Section 2 provides a theory of damage estimation. Section 3 describes the methodology and data. Section 4 presents calculating results of typhoon damages. Section 5 concludes.

\section{THEORY OF DAMAGE ESTIMATION}

The theoretical foundation used in this paper is from Mendelsohn and Saher $(2011)^{5)}$. The economic damage $(D)$ from each tropical cyclone is the sum of all the losses caused by it. In this analysis, the lost buildings and infrastructures are focused on. The economic damage of capital losses is the present value of lost future rents. This should be equal to the market value of the building. Note that the market value of capital is often less than the replacement cost

We assume that $L_{i j}$ is a vector of losses from tropical cyclone $i$ in location $j$. These losses can take many forms, including direct economic damages from capital and infrastructural destruction, human fatality, both temporary and permanent homelessness.

The losses are based on both a vector of characteristics (e.g. wind speed, centre pressure) from tropical cyclone $i$, when it makes landfall at location $j, X_{i j}$, and local socioeconomic factors, $Z_{i j}$ in location $j$ when storm $i$ hits:

$$
L_{i j}=L\left(X_{i j}, Z_{i j}\right)
$$

The losses increase in the intensity of the typhoon $\frac{d L}{d X}>0$, but losses can either increase or decrease in socioeconomic characteristics. For example, as income increases, there may be more capital in harm's way to be damaged. On the other hand, if protection is a normal good, actors may take steps to reduce the magnitude of impacts through adaptation. Thus, the direction of impact for socioeconomic variables remains an empirical question.

The probability, $I_{i j}$ that storm $i$ will make landfall in location $j$ during a given period of time depends on both the storm characteristics, $X_{i j}$, and the climate, $C$ :

$$
\Pi_{i j}=\Pi\left(X_{i j}, C\right)
$$

The probability of landfall decreases as the strength of the storm increases $\frac{d I I}{d X}<0$. The direction of impact of climate is an empirical question.

Expected losses in a given region, $E[L]$, equal total losses multiplied by the probability of landfall, integrated over all landfalls and locations within the region:

$$
E[L]=\iint_{I} \Pi\left(X_{i j}, C\right) L\left(X_{i j}, Z_{i j}\right) d J d I
$$

With this framework, the impact of socioeconomic and climate change is calculated. The socioeconomic change impact, $S C$, is equal to expected losses after a change in socioeconomic characteristics minus the expected losses before the change, holding all other factors including climate constant at the current levels:

$$
S C=E\left[L\left(Z_{1}, C_{0}\right)\right]-E\left[L\left(Z_{0}-C_{0}\right)\right]
$$

Additionally, $C C$, the impact of climate change on cyclone losses, is equal to the expected losses after a change in climate minus the magnitude of expected losses before the climate has changed:

$$
C C=E\left[L\left(Z_{1}, C_{1}\right)\right]-E\left[L\left(Z_{1}-C_{0}\right)\right]
$$

To separately isolate the impacts of $S C$ and $C C$, it is important to hold everything else constant at the correct levels. For $S C$, we hold climate constant at the present value. For $C C$, we hold socioeconomic factors constant at the future level.

Where $Z_{1}, Z_{0}$ denote socioeconomic factors at future level and current conditions and $C_{1}, C_{0}$ are the climate factors at future and current conditions respectively.

\section{DATA AND METHODOLOGY}

\section{(1) Data}

\section{a) Data on tropical cyclone damages}

The data on tropical cyclone damages are obtained from EM-DAT ${ }^{6}$, the International Disaster Database 
Table 1. The population, GDP, area, income per capita, and population density of Vietnam in 2007 and 2100.

\begin{tabular}{|l|r|r|r|}
\hline \multirow{2}{*}{ Year } & \multirow{2}{*}{$\mathbf{2 0 0 7}$} & \multicolumn{2}{c|}{$\mathbf{2 1 0 0}$} \\
\cline { 3 - 4 } & & \multicolumn{1}{c|}{ SSP3 } & \multicolumn{1}{c|}{ SSP5 } \\
\hline Population & $84,218,500$ & $112,116,053$ & $112,116,053$ \\
\hline $\begin{array}{l}\text { GDP } \\
\left(10^{9} \text { VND) }\right.\end{array}$ & $1,248,081$ & $5,462,074$ & $68,452,474$ \\
\hline $\begin{array}{l}\text { GDP per } \\
\text { capita }(\mathrm{VND})\end{array}$ & $14,819,559$ & $48,718,040$ & $610,550,157$ \\
\hline Area $\left(\mathrm{km}^{2}\right)$ & 331,000 & 331,000 & 331,000 \\
\hline $\begin{array}{l}\text { Pop density } \\
\left.\text { (Pop. per km }{ }^{2}\right)\end{array}$ & 254 & 339 & 339 \\
\hline
\end{tabular}

managed by the Centre for Research on the Epidemiology of Disasters. The EM-DAT database includes information on natural and technological disasters and is sponsored in Vietnam.

\section{b) Changes in socioeconomic and population density of Vietnam.}

The change in the socioeconomic projection of Vietnam is based on SSPs scenarios for low-income countries ${ }^{7}$. Here, we use two scenarios in changing of GDP per capita growth rates SSP3, and SSP5, the lowest and highest growth rate scenarios respectively. Variation of population density in the future is based on the United Nation ${ }^{8)}$ about world population in 2300. The authors based on the socioeconomic conditions of Vietnam in the past and future, the money and currency were converted to the U.S. dollars in 2007. After that, the authors transferred into VND. Calculating results present in Table 1.

\section{c) Numerical simulation of Typhoon Lekima.}

In the current study, the pseudo global warming (PGW) downscaling approach ${ }^{9)}$ was applied to investigate the future variation of tropical cyclone intensity in the coastal regions of Vietnam. For this purpose, we selected Typhoon Lekima from 2007 and estimate the intensity of it at current (CTL) and PGW simulations. For assessment of future global warming, we used future climate projections by $8 \mathrm{GCMs}$ in the $3^{\text {rd }}$ phase of Coupled Model Intercomparision $(\mathrm{CMIP} 3)^{10)}$. The name of GCMs are listed in Table 2. The future climate projections used in this study were coupled atmosphere-ocean global climate models (AOGCM) outputs under the Special Report on Emissions Scenario A1B. Weather Research and Forecasting model (WRF) version 3.6.1 was adopted for the CTL and PGW simulations.

Errors in initial conditions and in model physics result in forecast uncertainties. One approach for reducing these uncertainties is the use of ensemble forecasting. In this research, ensemble simulations with different initial conditions were performed for the CTL and each PGW conditions. At first, the lagged average forecast (LAF) method was used to obtain three different simulations. From three different simulations, we made sixteen new ensemble members. In total, 19

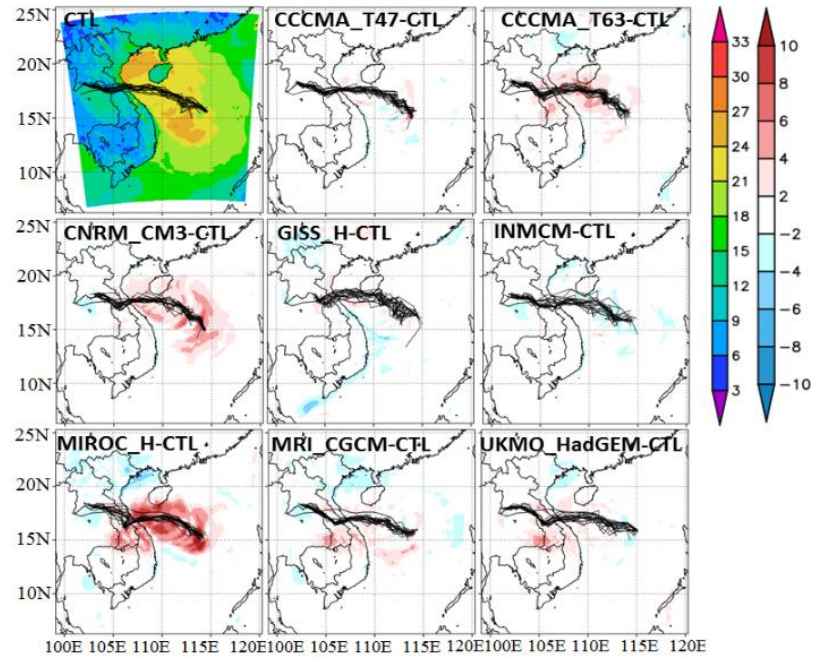

Fig 2. The distribution of current maximum wind speed, different maximum wind speed between current and future, and tracks of Typhoon Lekima. Left- and right-hand colour bars are for the maximum wind speed of CTL and the differences between PGW and CTL $(\mathrm{m} / \mathrm{s})$ respectively.

Table 2. The results of average maximum wind speed at landfall of Lekima typhoon with different scenarios.

\begin{tabular}{|l|l|r|r|}
\hline Climate models & Climate & \multicolumn{1}{c|}{$\begin{array}{c}\text { Wind speed } \\
(\mathbf{k m} / \mathbf{h})\end{array}$} & $\begin{array}{c}\text { \% change } \\
\text { wind speed }\end{array}$ \\
\hline CTL & Current & 96.12 & \\
\hline CCCMA_T47 & Future & 94.92 & $-1.26 \%$ \\
\hline CCCMA_T63 & Future & 92.52 & $-4.25 \%$ \\
\hline CNRM_CM3 & Future & 99.23 & $3.14 \%$ \\
\hline GISS_H & Future & 105.23 & $8.67 \%$ \\
\hline INMCM & Future & 85.58 & $-12.31 \%$ \\
\hline MIROC_H & Future & 85.28 & $-12.70 \%$ \\
\hline MRI_CGCM & Future & 88.87 & $-8.15 \%$ \\
\hline UKMO_HadGEM & Future & 84.97 & $-13.14 \%$ \\
\hline
\end{tabular}

simulations were made. For more details of this methodology, refer to Tran and Taniguchi (2016) ${ }^{11)}$.

Simulation Results of the difference of Typhoon Lekima intensity (maximum wind speed) between CTL and PGW simulations show in Figure 2.

The differences of maximum wind speed between PGW and CTL runs are shown in Figure 2. In CCCMA_T63, CNRM_CM3, and MIROC_H experiments, there will be an increase in maximum wind speed and the strong wind will concentrate in the central regions of Vietnam and tends to shift to the southern in the future. In GISS_H and INMCM show a slight decrease in maximum wind speed comparing with CTL runs. However, when Typhoon Lekima made landfall, the GISS_H simulation gave the highest value, and the second was CNRM_CM3 with $105.23 \mathrm{~km} / \mathrm{h}$, and $99.23 \mathrm{~km} / \mathrm{h}$ respectively. Simulation result of UKMO_HadGEM was the smallest of $84.97 \mathrm{~km} / \mathrm{h}$ when comparing with $96.12 \mathrm{~km} / \mathrm{h}$ of CTL runs. At the landfall, wind speed is smaller in PGW runs. This may be caused by difference in location of landfall. The average maximum wind speed in the future listed in Table 2. 
Table 3. The estimated coefficients in damage functions

\begin{tabular}{|l|c|l|c|}
\hline Variable & Coefficients & \multicolumn{1}{|c|}{ Variable } & Coefficients \\
\hline $\mathrm{B}_{\mathrm{o}}$ & 0.972 & $\mathrm{~B}_{3}$ & 2.819 \\
\hline $\mathrm{B}_{1}$ & 0.864 & $\varepsilon$ & 0.971 \\
\hline $\mathrm{B}_{2}$ & 0.591 & $\mathrm{~N}^{\mathrm{o}}$ of observations & 46 \\
\hline
\end{tabular}

\section{(2) Estimation of economic losses}

We use historical data to estimate the relationship between cyclone intensity and direct economic damages.

The damage per storm $(D)$ was regressed on intensity (Z) (with the Vietnam data), population density (Pop), and income per capita $(Y)$ using storms since 1992 to 2014. The functional form of the regression is in the following form:

$\ln D=B_{o}+B_{1} \ln P o p+B_{2} \ln Y+B_{3} \ln Z+\varepsilon$

Where $(\varepsilon)$ is the error term and $(B i)$ are the estimated coefficients. Exponentiations both sides of the equation:

$$
D=B_{o} \times \operatorname{Pop}^{B_{1}} \times Y^{B_{2}} \times Z^{B_{3}} \times \varepsilon
$$

Note that this functional form implies a constant elasticity relationship between the independent variable and damage equal to the coefficients. For example, 100 percent increase in income leads to a $B_{2}$ increase in damage. This functional form fits the data more closely than alternative semi-log or linear functional forms.

Table 3 displays parameters used in the damages functions for this analysis. To obtain these parameters, the Ordinary Least Squares estimator are used and regress damages on socioeconomic factors and tropical cyclone characteristics.

\section{RESULTS}

With the impact functions defined as Eq. 7 above, we estimate the changes in typhoon losses from both socioeconomic and climate change scenarios.

\section{(1) Climate change impact on tropical cyclone damages}

First, we consider the impact of climate change on tropical cyclone damages; we assume that the socioeconomic conditions of Vietnam do not change in the future; the tropical cyclone damages is only under the changing of typhoon intensity based on the Eq.5.

Figure 3 shows damage at the locations of landfall in ensemble simulations for current (CTL runs) and future climate conditions. Simulation results indicated that tropical cyclone losses are closely correlated to the storm intensity. Results of CTL and PGW runs shown that the average damage changed from VND 600 billion to approximately VND 1.000 billion. The results from UKMO_HadGEM, MIROC_H, INMCM and

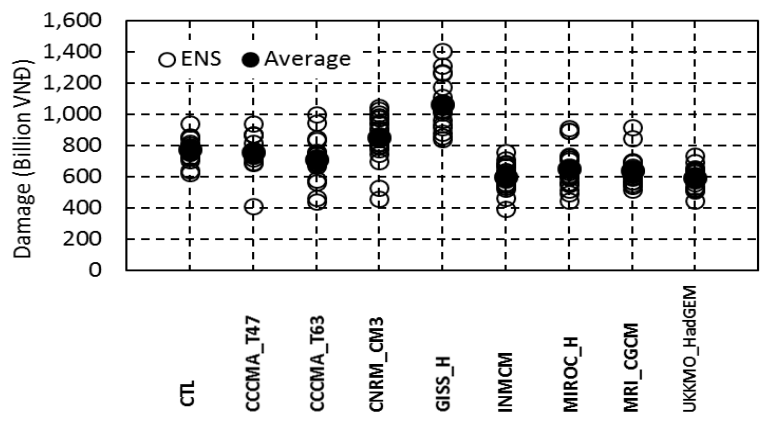

Fig 3. Damage of Typhoon at the location of landfall for each simulation and ensemble mean result under climate change.

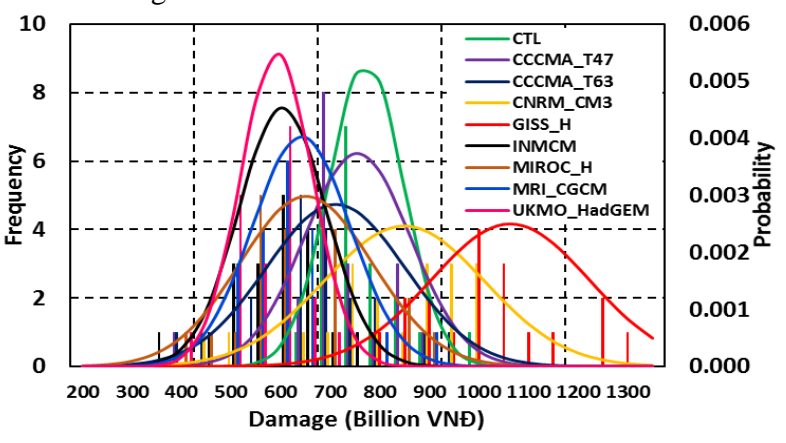

Fig 4. Frequency distributions and probability density curves of damages by eight PGW and CTL runs.

show decreases in the future, whereas, the results from GISS_H, CNRM_CM3 models give an increase in losses.

Figure 4 displays the probability density curves of damages by eight PGW simulations, and the CTL runs.

To describe the frequency and probability of economic losses caused by typhoon in the future, in this study, the authors assume normal distributions. However, other PDF may give better fitting.

There is a significant increase of losses in GISS_H and CNRM_CM3 models; it implies that a typhoon similar to Lekima will be more harmful when making landfall. However, frequency and probability of the damage will fall significantly in the future.

The damage from UKMO_HadGEM, INMCM, MIROC_H, and MRI_CGCM models will reduce when comparing with the losses of CTL runs.

\section{(2) Socioeconomic Change Impact on Tropical Cyclone Damages}

In this part, the future variations of damages with different socioeconomic and climate conditions are examined based on Eq.4. Both population density and income per capita are projected to 2100 . The population density in Vietnam is assumed to follow projections of United Nation about the world population to 2300 . The income capita to 2100 is based on the SSPs scenarios. The scenario with the 


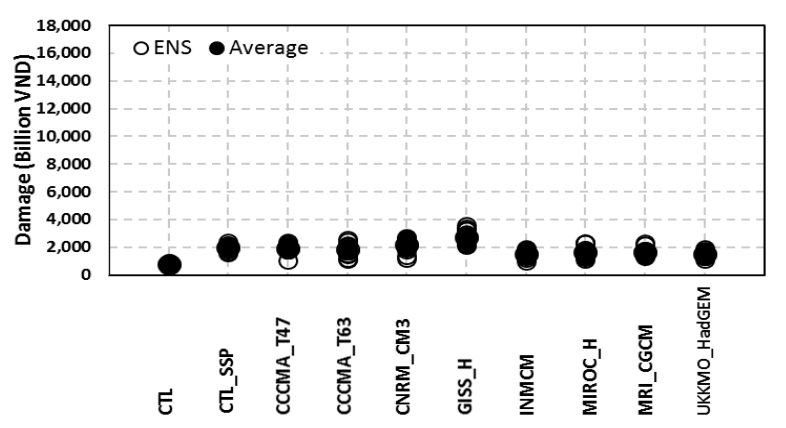

Fig 5. Damage of Typhoon Lekima for each simulation and ensemble mean result based on the SSP3 scenario and climate change.

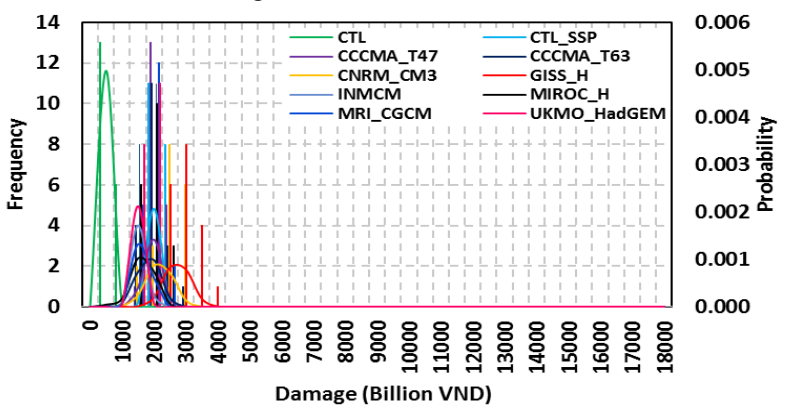

Fig 6. Frequency distributions and probability density curves of damages by eight PGWs, CTL_SSP and CTL run based on SSP3 scenario.

lowest increase in income per capita (SSP3) and the highest (SSP5) for low income countries are used in this study. The results are shown in Table 1.

The damages are recalculated with the typhoon intensity in CTL runs, future population density and income per capita. With future conditions in the end of the $21^{\text {st }}$ century, the damage of typhoon Lekima will increase in both SSP3 and SSP5 scenarios.

Figure 5 shows the maximum damages of Typhoon Lekima with the SSP3 scenario in eight PGW, CTL runs and CTL_SSP (current climate and future socioeconomic conditions). All PGW runs, and CTL_SSP runs show an increase in the losses of Typhoon Lekima.

The ensemble mean damage of CTL runs is approximately VND 772 billion. Whereas the GISS_H models gave the highest losses with nearly VND 2,734 billion. While the UKMO_HadGEM model gave the lowest with VND 1,520 billion in losses.

For six other PGW runs on future climate, the damages are close to VND 2,000 billion; it means that with the future socioeconomic and climate conditions, the losses caused by a typhoon similar to Typhoon Lekima will be approximately two to four times higher than in CTL runs.

In Figure 6, there are clear shifts in the probability density curves of damage. The results indicate that a tropical cyclone similar to Lekima in the future with SSP3 scenario would cause stronger damage than in the



Fig 7. Damage of Typhoon Lekima for each simulation and ensemble mean result based on the SSP5 scenario and climate change.

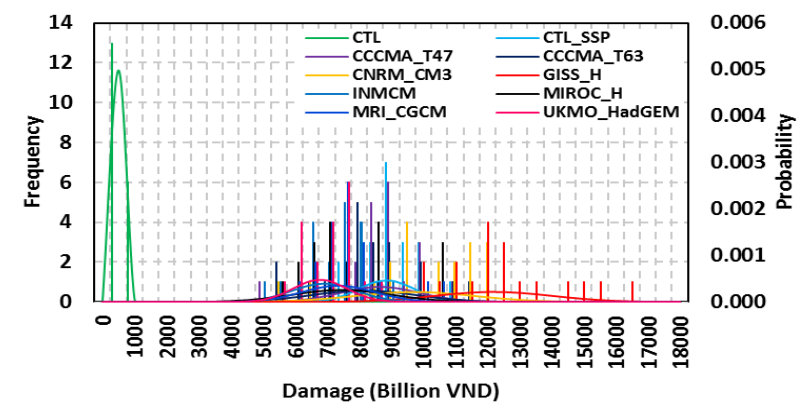

Fig 8. Frequency distributions and probability density curves of damages by eight PGW, CTL_SSP and CTL run based on SSP5 scenario.

current damages.

Figure 7 illustrates the simulation results of storm damages corresponding to a SSP5 scenario and climate change (the highest increase in income per capita). In this case, there is a dramatic increase in tropical cyclone losses. Especially, the ensemble mean results of GISS_H model is the highest, around VND 12,000 billion. The ensemble mean losses from INMCM, MIROC_H, MRI-CGCM, CCCMA_T63, T67, and UKMO_HadGEM, is approximately VND 6,100 billion, while the damage of CTL runs is VND 772 billion. However, the losses of CTL_SSP increases to 8,850 billion. The main reason for rising losses of tropical cyclone are the economic and population density increasing significantly in Vietnam in the future.

Figure 8 presents probability density curves of maximum damages simulated by eight PGW, the CTL runs, and CTL_SSP. It is clear that there is a significant increase of losses in all models runs, and CTL_SSP, the results indicate that large damage events will occur in the conditions of socioeconomic development in the future.

Overall, in this paper, with different scenario from socioeconomic development and climate, the results of tropical cyclone damages indicate that the losses caused by tropical cyclone will increase significantly and be proportional to socioeconomic development, overpopulation in the future and changing in socioeconomic conditions. Mendelsohn and Saher (2011) also showed that the damages of typhoon under the 
change of population density and income per capita is over 3 fold increase when comparing with current conditions ${ }^{5)}$. Considering variations in socioeconomic conditions are indispensable to estimate future risk of meteorological disasters.

\section{CONCLUSION}

This study aims to perform the losses caused by Tropical Cyclone Lekima on the Vietnam Central Coast from 30 September to 04 October 2007 and investigate the variations in losses under global warming conditions and socioeconomic changes in the future. In the current circumstances of climate and socioeconomic, the storm damages are close to observation data, the fluctuation of tropical cyclone losses was wide among ensemble members of CTL runs and eight GCMs of CMIP3. Moreover, with the future socioeconomic and current or future climate conditions, the storm damages will increase significantly. Storm losses were affected heavily by socioeconomic conditions. The losses by a Typhoon with SSP5 scenario are approximately six and sixteen times greater than SSP3 scenario and climate change scenarios respectively.

In this study, only one tropical cyclone was used to examine the variations of storm intensity and the conclusions drawn about changing in damages due to future global warming may include some uncertainty. So, further studies should examine with the different tropical cyclone events to accurately determine the variation of tropical cyclone intensity.

In this research, the variation of storm damages only refers to the change in tropical cyclone intensity, as well as the changing of socioeconomic conditions in the future. Losses vary a great deal if a storm hits a city versus a rural area, but this is not yet captured in this analysis. Increases in income and population density along the coast, about the rest of the country, will cause more damages.

We did not mention the number of deaths and missing, the damages of floods caused by torrential rains, and the sea level rise phenomenon. These will be the main reasons causing a lot of damages. From the research results of Tran and Taniguchi (2016), the heavy rain caused by Typhoon Lekima will be stronger in the future. So the damages caused by heavy rain may increase in the coastal regions of Vietnam. Hence, the next studies about the tropical cyclone losses should consider and solve this missing dimension to the problem.

It is thought that the results of this study are the first step in evaluating damages due to tropical cyclones, and investigation of other tropical cyclones, as well as the use of additional climate scenario, socioeconomic variation scenarios, and the different damages caused by storms, such as the number of deaths, missing, the damages from flood and sea level rise, will be indispensable for assessing changes in storm losses in the future.

ACKNOWLEDGEMENT: The authors are grateful for the use of EMDAT, International Disaster Database and to all research institutes contributing to this activity. We would like to thank General Statistics Office of Vietnam providing socioeconomic and population density datasets in the past. The authors would like to thank anonymous reviewers for their helpful comments and suggestions for improving the quality of the manuscript.

\section{REFERENCES}

1) IPCC, 2014: Climate Change 2014: Synthesis Report. Contribution of Working Groups I, II and III to the Fifth Assessment Report of the Intergovernmental Panel on Climate Change, Change [Core Writing Team, R.K. Pachauri and L.A. Meyer (eds.)], IPCC, Geneva, Switzerland, 151 pp, 2014.

2) Pielke Jr, R.A. and C.W. Landsea.: Normalized hurricane damages in the United States: 1925-95, Weather and Forecasting 13, 3, pp. 621-631, 1998.

3) Narita, D., et al.: Damage costs of climate change through intensification of tropical cyclone activities: An application of FUND, Climate Research, 39, pp. 87-97, 2008.

4) Garcia, L.: Overview of early warning systems for hydrometeorological hazards in selected countries in Southeast Asia, Asian Disaster Preparedness Center, Thailand, 2002.

5) Mendelsohn, R. and G. Saher.: The global impact of climate change on extreme events, World Bank Washington, DC, 2011.

6) D. Guha-Sapir, R. Below, Ph. Hoyois - EM-DAT.: International Disaster Database - www.emdat.be, Universite Catholique de Louvain, Brussels, Belgium.

7) Leimbac, M., et al.: Future growth patterns of world regions - A GDP scenario approach, Global Environmental Change, pp. 1-11, 2015.

8) United Nations.: World Population in 2300 Department of Economic and Social Affairs, New York, 2004.

9) Sato, T., Kimura, F. and Kitoh, A.: Projection of global warming onto regional precipitation over Mongolia using a regional climate model, J. Hydrol, 333, p144-154, 2007

10) Meehl, G., Covey, C., Delworth, T., Latif, M., McAvaney, B., Mitchell, J., Stouffer, R. and Taylor, K.: The WCRP CMIP3 multimodel dataset, Bull. Am. Meteorol. Soc, 88, 1383-1394, 2007.

11) Tran, L.Q. and K. Taniguchi.: Simulations of Heavy Rainfall from a Tropical Cyclone in Coastal Regions of Vietnam under the Global Warming, Journal of Climate change, Vol. 2, No. 2, pp. 25-34, 2016.

(Received September 30, 2016) 